\title{
ON AN APPROACH IN SERVICE OF MEAN-INEQUALITIES
}

\section{MUSTAPHA RAÏSSOULI}

Abstract. In the present paper, an approach for constructing new means in two variables is investigated. Application of this approach for proving some mean-inequalities is also discussed.

Mathematics subject classification (2010): 26E60.

Keywords and phrases: Bivariate means; regular means; inequalities between means.

\section{REFERENCES}

[1] P. S. Bullen, Handbook of Means and Their Inequalities, Mathematics and Its Applications, Springer, 2nd edition, 1987.

[2] I. Costin And Toader, Invariance in the Class of Weighted Lehmer Means, J. Ineq. Pure. Appl. Math., Vol. 9 (2008), No. 2, Art. 54, 7 pp.

[3] E. Neuman And J. SÁndor, On the Schwab-Borchardt Mean, Math. Pannonica 14/2 (2003), $253-$ 266.

[4] E. Neuman And J. SÁndor, On the Schwab-Borchardt Mean II, Math. Pannonica 17/1 (2006), 49-59.

[5] M. Raïssouli And J. SÁndor, On a Method of Constructiion of New Means with Applications, J. Ineq. Appl., 2013, 2013:89.

[6] J. SÁnDOR, On certain Inequalities for Means III, Arch. Math. 76 (2001), 34-40.

[7] H. J. SEIFFERT, Problem 887, Nieuw Arch. Wisk. 11 (1993), 176.

[8] H. J. SEIFFERT, Aufgabe 16, Wurzel 29 (1995), 87. 